reason for this is that health centres housing both general practitioners and local authority services are springing up in many places. The ministry seems to be convinced that this development will take an increasing proportion of the health service budget in the decade ahead.

The report also gives details of the total size of the budget and how it is divided among the competing branches of the scrvice. In 1965/66 the Health Service cost $f 1,241$ million, a figure expected to rise in $1966 / 67$ to $£ 1,367$ million. Hospitals account for about half the total budget ( $£ 687$ million on current expenditure and $\mathfrak{E} 81$ million on capital expenditure in $1966 / 67)$. Drugs will cost $£ 142$ million this year, local health services $£ 127$ million, general medical services $£ 98$ million, and dental services $\mathfrak{f 7 0}$ million. Income from patients in $1966 / 67$ is expected to be about $£ 19$ million. Faced with figures like these, it is easy to understand the problems which the minister, Mr Kenneth Robinson, must face when he asks the Treasury for more. It is also easy to see why the doctors were driven to suggest in Bristol that more of the cost of the service should be carried by the patients. Ignoring the most extreme attitudes, sometimes expressed in the claim that the relationship between patients and doctors would somehow be magically transformed for the better when money is allowed to change hands, there may nevertheless be a case for saying that the Health Service will have to become more selective.

\section{Boom in Physics}

The Institute of Physics and the Physical Society (which is the name of a single learned society based in London) is evidently pleased with its own growth in the past year and the prospects for extending its activities into Europe in the immediate future. In the annual report of the council of the Institute of Physics and the Physical Society presented to the annual general mecting on July 4, membership is said to have increased by 10 per cent to a total of 12,350 at the end of 1966. Although this implies a more rapid increase than that of the moncy being spent on research in physics, the Institute of Physics and the Physical Socicty is disappointed that its membership includes fewer than half of those eligible for membership.

The European venture is now apparently reaching a point at which decisions will be possible, and a stcering committee under Professor G. Bernadini has been circulating the draft of a constitution for a federation of physical societies on a European basis. It is hoped that reactions to the proposals will be sufficiently well known by October or November for the steering committee to settle for a final version of the constitution. By all accounts, everything is going well, and the chances are high that by the end of the ycar or the beginning of 1968 a federal physical society will be in being.

Commercially, the Tnstitute of Physics and the Physical Society continues to do well. In 1966 it was able to transfer $£ 10,674$ to the reserves on a turnover of $£ 279,000$. More than a third of its income comes from the salc of publications. This year, in contrast, with 1965, profit on publications has been largely swallowed up by the cost of launching the new journal Physics Education-a venture which in commercial terms cannot be expected to break even for some years after its foundation. In its report, the council has included graphs which show that the numbers of words of text printed in its journals are growing less rapidly than might have been expected. With the Proceedings of the Physical Society, for example, bulk has increased by only 50 per cent since 1961. The British Journal of Applied Physics has not grown in bulk since 1964.

At the meeting on July 4, Dr A. D. I. Nicol (Cambridge) was elected a vice-president of the Institute of Physics and the Physical Society, P. 'T. Menzies honorary treasurer, Dr R. Press honorary secretary, and Professors S. F. Edwards and C. A. Hogarth members of council.

\section{Hopeful Forecast}

CoNSIDERABLE improvements in weather forecasting were achieved during 1966, according to the report of the Mcteorological Office for that year. Two reasons are given; first the acquisition of equipment for the automatic drawing of forecast charts for 48 hour forecasts (described in Nature, 214, 230; 1967) and secondly an improved method for detecting the small scale changes which are one of the hardest problems of weather forecasting. This new approach uses a sophisticated model of the atmosphere, taking account of the water vapour in the air, and predicts pressure, temperature, wind and rainfall at hundreds of places 25 miles apart. To make the best use of the new method, though, the office will need a much faster computer; for a 24 hour forecast, the Atlas takes no less than eight hours to produce results.

The report preens itself a little about the report of the Estimates Committee of the House of Commons, which examined meteorological services during the year. Apart from congratulating the Meteorological Office on its efficiency, the committee seems to have agreed with the Office diagnosis of what needs to be done. A major expansion at Bracknell to overcome the shortage of space is one suggestion warmly welcomed by Dr B. J. Mason, Director of the Office. There also seem to be staff difficulties, principally in the scientific assistant grade where the recruitment rate cannot keep up with the resignations. There is also a shortage of experimental officers trained in experimental physics, electronics and computing, and these will have to bo recruited on a much larger scale.

A new departure was the establishment of a Cloud Physics Branch at Bracknell. This includes a laboratory physics group transferred en masse with Dr Mason from Imperial College London, a cloud dynamics group, and a radar unit. To get the best from the branch, Dr Mason hints, new aircraft will be needed for the Research Flight. The Office has also flown experiments in rockets during the year, and one to study molecular oxygen in the British satellite UK 3. During the year regular direct reception of pictures began from the weather satellites launched by NASA; these have been very useful in weather analysis and forecasting. Difficulties of recruitment are aggravated by the lack of suitable university courses in Britain, and for some years the gap has been filled by the Meteorological Office 'Training School, Dr Mason reports that, at last, new accommodation has been found for the school, which will move from Stanmore to Shinfield Park in Reading at the end of 1968. 